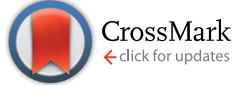

Cite this: J. Mater. Chem. A, 2015, 3, 19107

Received 7th April 2015

Accepted 9th August 2015

DOI: $10.1039 / c 5 t a 02514 a$

www.rsc.org/MaterialsA
View Journal | View Issue

\section{A new $\mathrm{CO}_{2}$-resistant Ruddlesden-Popper oxide with superior oxygen transport: A-site deficient $\left(\operatorname{Pr}_{0.9} \mathrm{La}_{0.1}\right)_{1.9}\left(\mathrm{Ni}_{0.74} \mathrm{Cu}_{0.21} \mathrm{Ga}_{0.05}\right) \mathrm{O}_{4+\delta}$}

\author{
Jian Xue, ${ }^{a}$ Qing Liao, ${ }^{c}$ Wei Chen, ${ }^{\text {b }}$ Henny J. M. Bouwmeester, ${ }^{\star b}$ Haihui Wang ${ }^{\star c d}$ \\ and Armin Feldhoff*a
}

A-site deficient $\left(\operatorname{Pr}_{0.9} \mathrm{La}_{0.1}\right)_{1.9} \mathrm{Ni}_{0.74} \mathrm{Cu}_{0.21} \mathrm{Ga}_{0.05} \mathrm{O}_{4+\delta}\left((\mathrm{PL})_{1.9} \mathrm{NCG}\right)$, with the $\mathrm{K}_{2} \mathrm{NiF}_{4}$ structure, is found to exhibit higher oxygen transport rates compared with its cation-stoichiometric parent phase. A stable oxygen permeation flux of $4.6 \times 10^{-7} \mathrm{~mol} \mathrm{~cm}{ }^{-2} \mathrm{~s}^{-1}$ at $900{ }^{\circ} \mathrm{C}$ at a membrane thickness of $0.6 \mathrm{~mm}$ is measured, using either helium or pure $\mathrm{CO}_{2}$ as sweep gas at a flow rate of $30 \mathrm{~mL} \mathrm{~min}{ }^{-1}$. The oxygen flux is more than two times higher than that observed through A-site stoichiometric $(\mathrm{PL})_{2.0} \mathrm{NCG}$ membranes operated under similar conditions. The high oxygen transport rates found for $(\mathrm{PL})_{1.9} \mathrm{NCG}$ are attributed to highly mobile oxygen vacancies, compensating A-site deficiency. The high stability against carbonation gives $(\mathrm{PL})_{1.9} \mathrm{NCG}$ potential for use, e.g., as a membrane in oxy-fuel combustion processes with $\mathrm{CO}_{2}$ capture.

\section{Introduction}

Clean energy delivery technologies are imperatively required for the purpose of reducing the emission of $\mathrm{CO}_{2}$ to avert global climate change. Oxygen-transport membranes (OTMs) based on mixed electronic and ionic conductors have gained increasing attention due to their economical, efficient, and environmentally friendly production of oxygen from air and their potential integration in oxy-fuel technologies with $\mathrm{CO}_{2}$ capture. ${ }^{1,2}$ In the oxy-fuel process, a part of the flue gas, which contains $\mathrm{CO}_{2}$, is recycled and used as sweep gas. Therefore, oxygen-transport membranes should not only exhibit a high oxygen flux, but also show good stability under $\mathrm{CO}_{2}$-containing atmospheres. ${ }^{3,4}$

Acceptor-doped perovskite-type oxides $\mathrm{A}_{1-x} \mathrm{~A}_{x}{ }^{\prime} \mathrm{B}_{1-y} \mathrm{~B}_{y} \mathrm{O}_{3-\delta}$ ( $\mathrm{A}, \mathrm{A}^{\prime}=\mathrm{La}, \mathrm{Sr}, \mathrm{Ba} ; \mathrm{B}, \mathrm{B}^{\prime}=\mathrm{Fe}, \mathrm{Co}, \mathrm{Nb}$, etc.) have been investigated extensively as OTMs over the past two decades. ${ }^{5,6}$ The ionic charge carriers created by acceptor-doping are mobile oxygen vacancies. Indeed, high oxygen fluxes are measured for materials with high concentrations of oxygen vacancies. Up to 1/4 of the oxygen sites can be vacant like, for example, $\mathrm{SrCo}_{0.8} \mathrm{Fe}_{0.2^{-}}$ $\mathrm{O}_{3-\delta}$ and $\mathrm{Ba}_{0.5} \mathrm{Sr}_{0.5} \mathrm{Co}_{0.8} \mathrm{Fe}_{0.2} \mathrm{O}_{3-\delta} \cdot{ }^{7,8} \mathrm{~A}$ drawback is that these materials are prone to carbonation. An oxygen-impermeable

${ }^{a}$ Institute of Physical Chemistry and Electrochemistry, Leibniz University Hannover, Callinstrasse 3A, D-30167 Hannover, Germany. E-mail: armin.feldhoff@pci. uni-hannover.de

${ }^{b}$ Department of Science and Technology, MESA+ Institute for Nanotechnology, University of Twente, 7500 AE Enschede, The Netherlands. E-mail: h.j.m. bouwmeester@utwente.nl

${ }^{c}$ School of Chemistry \& Chemical Engineering, South China University of Technology, No.381 Wushan Road, Guangzhou 510640, China.E-mail: hhwang@scut.edu.cn

${ }^{d}$ School of Chemical Engineering, The University of Adelaide, Adelaide, SA 5005, Australia alkaline-earth carbonate layer will be formed on the membrane surface exposed to the $\mathrm{CO}_{2}$-containing sweep gas, resulting in a decline of the oxygen permeation flux with time. ${ }^{9,10}$ A-site deficiency is commonly adopted in an attempt to lower the basicity, thereby increasing the resistance of the membrane material towards carbonation. ${ }^{\mathbf{1 1}}$

Alternatively, problems with limited $\mathrm{CO}_{2}$ stability could be avoided by the development of alkaline-earth-free membrane materials. In this regard, perovskite-related RuddlesdenPopper (RP) $\mathrm{A}_{n+1} \mathrm{~B}_{n} \mathrm{O}_{3 n+1}$ materials, in particular those with the $\mathrm{K}_{2} \mathrm{NiF}_{4}$ structure (the first member of the RP oxides with $n=1$ ), are attracting increasing attention. ${ }^{12,13}$ The latter structure consists of alternate $\mathrm{AO}$ rock-salt and $\mathrm{ABO}_{3}$ perovskite-like layers along the crystallographic $c$-axis, as shown in Fig. 1. Oxygen transport proceeds via migration of oxygen interstitials (O3) in the rock-salt layers. ${ }^{\mathbf{1 4 1 5}}$ Molecular dynamics (MD) simulations predict an interstitialcy diffusion mechanism, also referred to as a 'knock-on' or 'push-pull' mechanism, involving concerted jumps between interstitial oxygen (O3) and apical oxygen (O2) sites, rather than a direct jump between two interstitial sites. ${ }^{16} \mathrm{~A}$ contribution of vacancy-mediated transport may be considered, but this necessitates the formation of oxygen vacancies. Using atomistic computer simulation, Cleave et al. predicted that all of the vacancy mechanisms studied in $\mathrm{La}_{2} \mathrm{NiO}_{4}$ exhibit lower activation energies than the interstitial process. ${ }^{17}$ Most reported oxides with the $\mathrm{K}_{2} \mathrm{NiF}_{4}$ structure are, however, oxygen hyperstoichiometric so that in most of these cases the role of mobile interstitials is predominant. ${ }^{12,18}$

Using in situ high-temperature neutron powder diffraction, Yashima et al. provided evidence that indeed the ionic charge carriers in $\left(\mathrm{Pr}_{0.9} \mathrm{La}_{0.1}\right)_{2.0} \mathrm{Ni}_{0.74} \mathrm{Cu}_{0.21} \mathrm{Ga}_{0.05} \mathrm{O}_{4+\delta}\left((\mathrm{PL})_{2.0} \mathrm{NCG}\right)$ are oxygen interstitials. ${ }^{\mathbf{1 8 , 1 9}}$ It was determined that $(\mathrm{PL})_{2.0} \mathrm{NCG}$ 


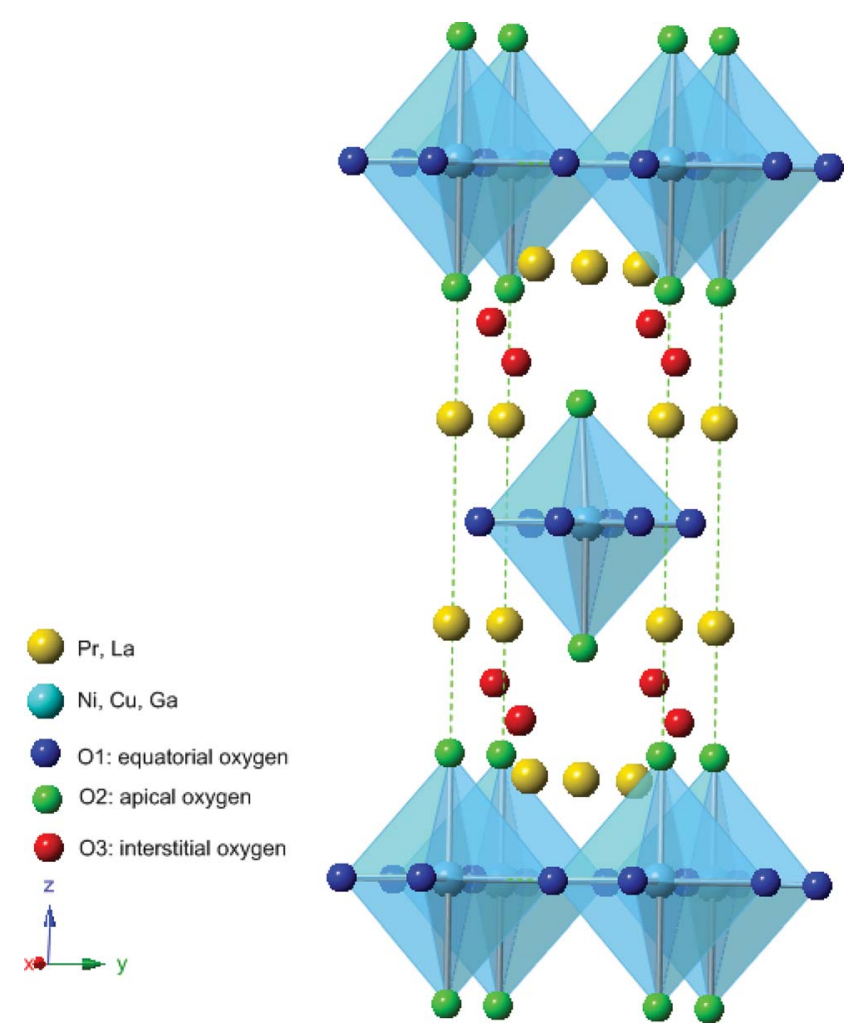

Fig. 1 Oxide with the tetragonal $\mathrm{K}_{2} \mathrm{NiF}_{4}$-type structure (space group $14 / \mathrm{mmm}$ ). Atomic positions were calculated from ICSD 173422. For clarity only a subset of the interstitial oxygen ions (O3) is shown.

exhibits specific thermal anisotropic temperature factors expected for migration via the interstitialcy mechanism. Interestingly, Ishihara and colleagues found that A-site deficient oxides $\mathrm{Nd}_{1.9}\left(\mathrm{Ni}_{0.75} \mathrm{Cu}_{0.25}\right)_{0.95} \mathrm{Ga}_{0.05} \mathrm{O}_{4}$ and $\mathrm{Pr}_{1.9} \mathrm{Ni}_{0.75} \mathrm{Cu}_{0.25}$ $\mathrm{Ga}_{0.05} \mathrm{O}_{4}$ exhibit higher oxygen fluxes than their cation-stoichiometric parent phases. ${ }^{\mathbf{2 0} 21}$ The authors, however, refrained from giving a clear explanation of the role of A-site deficiency in oxygen transport. In this work, we have investigated the influence of A-site deficiency of (PL) ${ }_{2.0}$ NCG on structural parameters, oxygen transport, and stability in $\mathrm{CO}_{2}$ atmospheres.

\section{Experimental}

\subsection{Preparation}

Powders of $\left(\mathrm{Pr}_{0.9} \mathrm{La}_{0.1}\right)_{1.9} \mathrm{Ni}_{0.74} \mathrm{Cu}_{0.21} \mathrm{Ga}_{0.05} \mathrm{O}_{4+\delta}\left((\mathrm{PL})_{1.9} \mathrm{NCG}\right)$ and $(\mathrm{PL})_{2.0}$ NCG were prepared by a combined citrate and ethylenediamine-tetraacetic-acid (EDTA) method as described previously. ${ }^{22,23}$ The as-prepared powders were uniaxially pressed at 20 MPa to obtain green pellets followed by their sintering in air at $1230{ }^{\circ} \mathrm{C}$ for $10 \mathrm{~h}$ in a bed of the corresponding powder. The density of the sintered disk membranes obtained was measured by the Archimedes method using distilled water. Only membranes with a relative density higher than 95\% were selected for permeation experiments. The membranes were polished to the desired thickness using 1200 grit-sandpaper and then washed with ethanol.

\subsection{Structural characterization}

The crystal structure of the sintered disks was studied by using an in situ X-ray diffractometer (XRD, D8 Advance, Bruker-AXS, with $\mathrm{Cu} \mathrm{K} \alpha$ radiation) equipped with a HTK-1200N hightemperature oven chamber (Anton-Paar). Measurements were conducted under a $\mathrm{CO}_{2}$ atmosphere from 30 to $1000{ }^{\circ} \mathrm{C}$. The temperature was step-wise increased, with a dwell time at each step of $50 \mathrm{~min}$ before actual data collection. The oxygen content of $(\mathrm{PL})_{1.9} \mathrm{NCG}$ and $(\mathrm{PL})_{2.0} \mathrm{NCG}$ in air at $900{ }^{\circ} \mathrm{C}$ was evaluated by hydrogen reduction in a thermogravimetric (TGA) apparatus (Netzsch TG $449 \mathrm{~F} 3$ ), assuming that the products of hydrogen reduction were $\operatorname{Pr}_{2} \mathrm{O}_{3}, \mathrm{La}_{2} \mathrm{O}_{3}, \mathrm{Ni}, \mathrm{Cu}$ and $\mathrm{Ga} .^{12,24}$ The microstructure of the disk membrane was examined by scanning electron microscopy (SEM) using a JEOL JSM-6700F field-emission instrument operating at an excitation voltage of $2 \mathrm{kV}$. The elemental composition of the membrane was determined by energy dispersive X-ray spectroscopy (EDXS), using an Oxford Instruments INCA-300 EDX spectrometer with an ultrathin window and at an excitation voltage of $20 \mathrm{kV}$.

\subsection{Oxygen permeation experiments}

The oxygen flux through the membranes with different thicknesses was investigated in the range of $800-975^{\circ} \mathrm{C}$ using a homemade high-temperature oxygen permeation cell, which is described in detail elsewhere. ${ }^{25,26}$ A commercial ceramic sealant (Huitian, Hubei, China) was used to seal the disk-shaped membrane onto an alumina tube. Synthetic air was fed $(150 \mathrm{~mL}$ $\min ^{-1}$ ) to the feed side of the membrane, while He or $\mathrm{CO}_{2}$ gas was fed to the sweep side. Unless specified otherwise a sweep gas flow rate of $30 \mathrm{~mL} \mathrm{m^{-1 }}$ was maintained. Gas flow rates were calibrated with a soap bubble flow meter. The composition of the effluent was analyzed by on-line gas chromatography (GC, Agilent Technologies, 7890A). The leakage of oxygen was subtracted in the calculation of the oxygen flux. ${ }^{25,27}$ The contribution of leakage to the apparent oxygen flux was below $0.5 \%$ in all cases.

\section{Results and discussion}

\subsection{Phase analysis and microstructure}

Fig. 2 shows the XRD patterns of (PL) ${ }_{1.9} \mathrm{NCG}$ and $(\mathrm{PL})_{2.0} \mathrm{NCG}$ ceramics after sintering at $1230{ }^{\circ} \mathrm{C}$ for $10 \mathrm{~h}$ in air. Analysis of the patterns confirms that both materials adopt the tetragonal $\mathrm{K}_{2} \mathrm{NiF}_{4}$ structure (ICDD PDF number: 01-087-1679). No impurity phases are detected..$^{\mathbf{2 8 9}}$ For a more precise evaluation of the influence of A-site deficiency on the XRD pattern, the reflections at $31.6^{\circ}, 69^{\circ}$ and $79^{\circ}$ are magnified and compared in Fig. $2 \mathrm{~b}-\mathrm{d}$, respectively. The 113 reflection of $(\mathrm{PL})_{1.9} \mathrm{NCG}$ at $31.6^{\circ}$ is slightly shifted to higher $2 \theta$ values compared to that of $(\mathrm{PL})_{2.0} \mathrm{NCG}$ as shown in Fig. 2b. The 324 and 400 reflections are shifted to a higher angle and merge with the 208 reflection, which is shifted to a lower angle, as shown in Fig. 2c. A similar phenomenon is found around $79^{\circ}$ as shown in Fig. 2d, where the 414 and 420 reflections are found to be merged with the 228 reflection. These observations are consistent with the different lattice parameters of $(\mathrm{PL})_{1.9} \mathrm{NCG}$ and $(\mathrm{PL})_{2.0} \mathrm{NCG}$, which are reported in Table 1. 
In situ XRD measurements were performed on (PL) ${ }_{1.9}$ NCG under a pure $\mathrm{CO}_{2}$ atmosphere from room temperature to $1000{ }^{\circ} \mathrm{C}$. As seen from Fig. 3, no additional reflections are found that would indicate the presence or formation of other phases, e.g., carbonates. The results are consistent with those from our previous study, in which it was found that (PL) $)_{2.0} \mathrm{NCG}$ also possesses excellent chemical stability under $\mathrm{CO}_{2}$ atmospheres. ${ }^{29,30}$

SEM micrographs of the (PL) ${ }_{1.9} \mathrm{NCG}$ and $(\mathrm{PL})_{2.0} \mathrm{NCG}$ membranes, which were sintered at $1230^{\circ} \mathrm{C}$ for $10 \mathrm{~h}$ in air, are presented in Fig. 4. As seen from this figure, both membranes show high density. The average grain area estimated from the micrographs is about $51 \mu \mathrm{m}^{2}$ for (PL) ${ }_{1.9} \mathrm{NCG}$, which is slightly higher than the value of $42 \mu \mathrm{m}^{2}$ found for (PL) ${ }_{2.0} \mathrm{NCG}$. Some fine-grained furnace dust particles are seen in both SEM micrographs. These could be successfully removed by polishing the membranes prior to permeation measurements as was revealed from SEM micrographs recorded after the polishing procedure.

Table 1 lists various properties of (PL) ${ }_{1.9} \mathrm{NCG}$ and $(\mathrm{PL})_{2.0} \mathrm{NCG}$. The unit cell parameters of both materials are close. Compared to $(\mathrm{PL})_{2.0} \mathrm{NCG}$, the lattice of $(\mathrm{PL})_{1.9} \mathrm{NCG}$ has shrunk slightly in the $c$-axis direction and has expanded slightly in the $a-b$ plane. ${ }^{31,32}$ Furthermore, (PL) ${ }_{1.9}$ NCG shows a higher relative
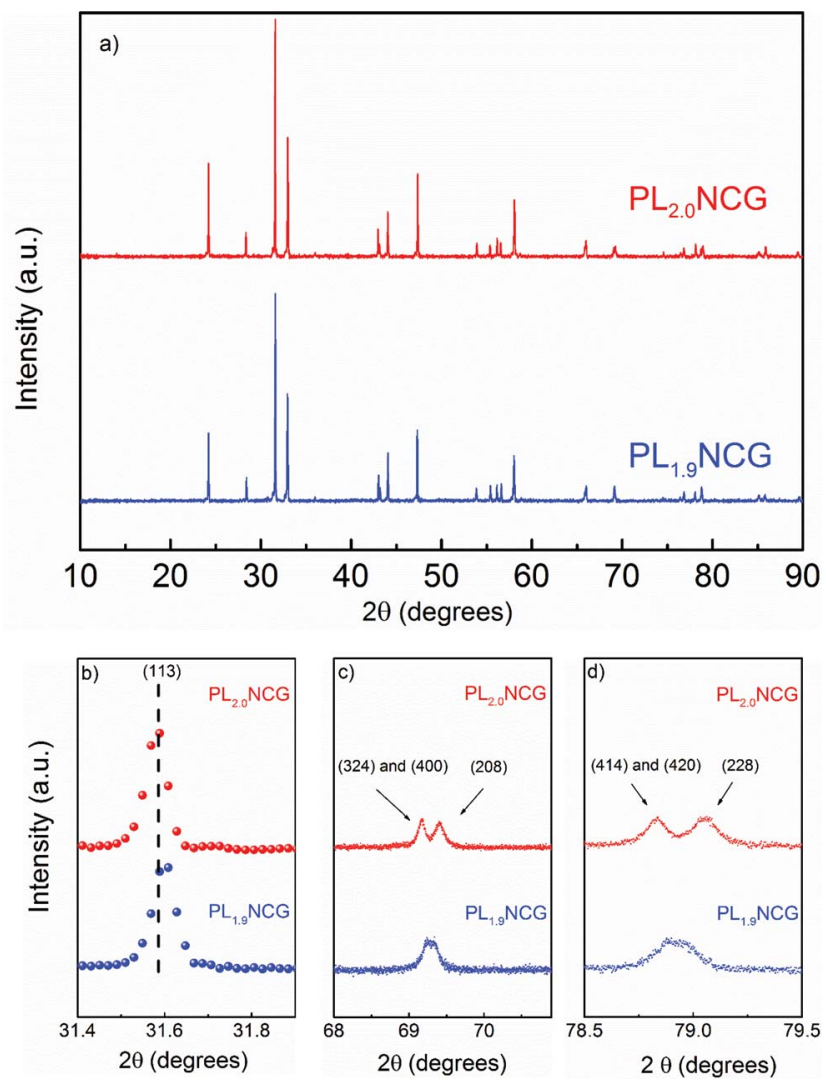

Fig. 2 (a) XRD patterns of $(\mathrm{PL})_{1.9} \mathrm{NCG}$ and $(\mathrm{PL})_{2.0} \mathrm{NCG}$ after sintering at $1230^{\circ} \mathrm{C}$ for $10 \mathrm{~h}$ in air, and (b) magnifications of selected regions of the patterns shown in (a). density, which might indicate that A-site deficiency enhances the sintering process. ${ }^{33}$ The average thermal expansion coefficient of $(\mathrm{PL})_{1.9} \mathrm{NCG}$ under a $\mathrm{CO}_{2}$ atmosphere is $15.9 \times 10^{-6} \mathrm{~K}^{-1}$, which is slightly higher than the value of $15.1 \times 10^{-6} \mathrm{~K}^{-1}$ observed for $(\mathrm{PL})_{2.0} \mathrm{NCG}$ under the same conditions. ${ }^{30}$ Note further that the oxygen content of A-site deficient (PL) ${ }_{1.9} \mathrm{NCG}$, at $900{ }^{\circ} \mathrm{C}$ in air, is significantly less than that observed for A-site stoichiometric $(\mathrm{PL})_{2.0} \mathrm{NCG}$. The latter suggests that A-site deficiency is mainly compensated by the removal of oxygen from the lattice.

\subsection{Oxygen flux}

An Arrhenius plot of the oxygen flux through a (PL) ${ }_{1.9}$ NCG membrane with a thickness of $0.6 \mathrm{~mm}$ is shown in Fig. 5. Also included are data of oxygen permeation for (PL) $)_{2.0} \mathrm{NCG}$ from our previous study. ${ }^{29}$ Similar oxygen fluxes are found whether using $\mathrm{He}$ or $\mathrm{CO}_{2}$ as sweep gas, albeit at the lowest temperatures the measured oxygen flux using $\mathrm{CO}_{2}$ as sweep gas tends to be slightly lower. The latter may be attributed to the adsorption of $\mathrm{CO}_{2}$ molecules at the surface, thereby blocking the surface exchange reaction. ${ }^{29,34}$ Compared to $(\mathrm{PL})_{2.0} \mathrm{NCG}$, slightly lower activation energies are found for A-site deficient (PL) ${ }_{1.9}$ NCG. Apparent activation energies in the temperature range of 800$975{ }^{\circ} \mathrm{C}$, using $\mathrm{He}$ as sweep gas, are 25 and $27 \mathrm{~kJ} \mathrm{~mol}^{-1}$ for $(\mathrm{PL})_{1.9} \mathrm{NCG}$ and $(\mathrm{PL})_{2.0} \mathrm{NCG}$, respectively. At $900{ }^{\circ} \mathrm{C}$, the oxygen flux through (PL) ${ }_{1.9} \mathrm{NCG}$ is $4.6 \times 10^{-7} \mathrm{~mol} \mathrm{~cm}^{-2} \mathrm{~s}^{-1}$ irrespective of the use of $\mathrm{CO}_{2}$ or He as sweep gas. The observed oxygen flux is more than two times higher than the value of $1.9 \times 10^{-7} \mathrm{~mol}$ $\mathrm{cm}^{-2} \mathrm{~s}^{-1}$ observed for (PL) ${ }_{2.0} \mathrm{NCG}$ under the same conditions. ${ }^{29}$ A-site cation deficiency thus has a large influence on the oxygen permeability.

The oxygen flux was further investigated as a function of membrane thickness. Oxygen permeation through dense mixed-conducting oxide membranes is governed by bulk diffusion and surface exchange. If bulk diffusion is the rate limiting step, the flux can be described by the Wagner equation,, 535

$$
j \mathrm{O}_{2}=-\frac{R T}{4^{2} F^{2} L} \frac{\sigma_{\mathrm{e}} \sigma_{\mathrm{i}}}{\sigma_{\mathrm{e}}+\sigma_{\mathrm{i}}} \ln \frac{p \mathrm{O}_{2}^{\prime}}{p \mathrm{O}^{\prime \prime}{ }_{2}}
$$

where $j \mathrm{O}_{2}, R, F, T, L, \sigma_{\mathrm{e}}$, and $\sigma_{\mathrm{i}}$ denote the oxygen flux, gas constant, Faraday constant, temperature, membrane thickness, and the partial electronic and ionic conductivity, respectively. $p \mathrm{O}^{\prime}{ }_{2}$ is the oxygen partial pressure maintained at the feed side, while $p \mathrm{O}^{\prime \prime}{ }_{2}$ is the oxygen partial pressure at the sweep side. Hence, if the oxygen flux is entirely governed by bulk diffusion, the plot of the normalized oxygen flux $\mathrm{O}_{2} / \ln \left(\mathrm{pO}^{\prime}{ }_{2} / \mathrm{pO}^{\prime \prime}{ }_{2}\right)$ versus reciprocal thickness $(1 / L)$ should be linear with the line intersecting the origin. Fig. 6 shows that the normalized oxygen fluxes for both (PL) 1.9 $_{\text {NCG }}$ and (PL) ${ }_{2.0}$ NCG increase proportionally with $1 / L$ for thicknesses greater than approximately 1.6 $\mathrm{mm}\left(1 / L=0.635 \mathrm{~mm}^{-1}\right)$, but depart from a linear relationship for smaller thicknesses. These results reveal that the oxygen flux is predominantly limited by bulk diffusion for a membrane thickness greater than $\sim 1.6 \mathrm{~mm}$ and by surface exchange for smaller thicknesses. 
Table 1 Various parameters of $(\mathrm{PL})_{1.9} \mathrm{NCG}$ and $(\mathrm{PL})_{2.0} \mathrm{NCG}$. Values between parentheses are standard deviations. Experimental data were acquired from sintered ceramics or powder obtained from crushed ceramics

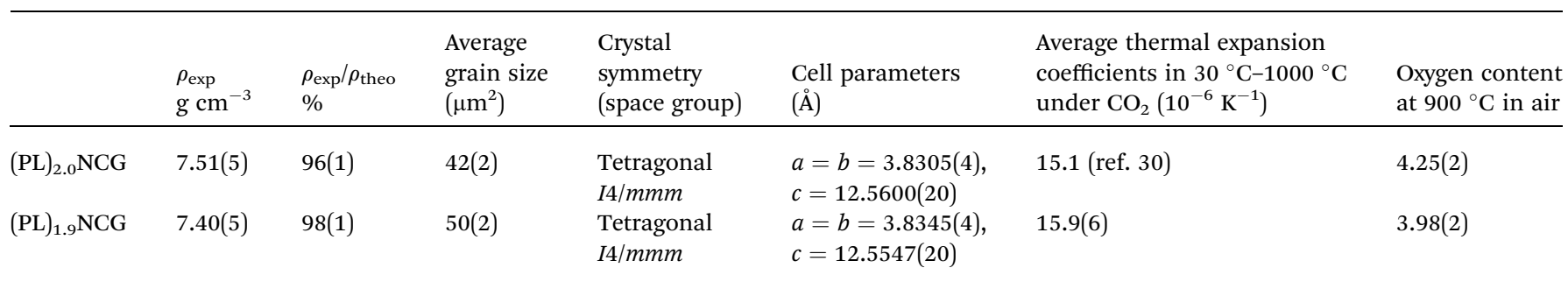

Since in both $(\mathrm{PL})_{1.9} \mathrm{NCG}$ and $(\mathrm{PL})_{2.0} \mathrm{NCG}$ the electronic conductivity predominates over the ionic conductivity, eqn (1) can be simplified to

$$
j \mathrm{O}_{2}=-\frac{R T}{4^{2} F^{2} L} \sigma_{\mathrm{i}} \ln \frac{p \mathrm{O}_{2}^{\prime}}{p \mathrm{O}^{\prime \prime}{ }_{2}}
$$

Using this equation, the ionic conductivity was calculated from the data of oxygen permeation measurements obtained for 2.3 mm thick membranes. At $900{ }^{\circ} \mathrm{C}$, a value of $0.21 \mathrm{~S} \mathrm{~cm}^{-1}$ is found for A-site deficient (PL) ${ }_{1.9} \mathrm{NCG}$, to be compared with $0.10 \mathrm{~S} \mathrm{~cm}^{-1}$ found for A-site stoichiometric $(\mathrm{PL})_{2.0} \mathrm{NCG}$. Increasing the sweep gas flow rate increases the oxygen partial pressure gradient across the membrane. Fig. 7 shows that the oxygen flux measured through a $0.6 \mathrm{~mm}$ thick membrane of $(\mathrm{PL})_{1.9} \mathrm{NCG}$ at different temperatures increases upon increasing the flow rate of the He sweep gas.

\subsection{Stability under $\mathrm{CO}_{2}$}

High oxygen flux and good chemical stability are two key factors for industrial application of oxygen transport membranes. Good $\mathrm{CO}_{2}$ resistance was found for the A-site stoichiometric $(\mathrm{PL})_{2.0} \mathrm{NCG}^{29}$ To assess the stability of A-site deficient (PL) ${ }_{1.9}$ NCG against carbonation, the oxygen permeation performance was studied by periodically changing the sweep gas between $\mathrm{He}$ and $\mathrm{CO}_{2}$. As can be seen from Fig. 8, only a marginal, reversible change of the oxygen flux occurs when the sweep gas is switched back and forth between He and $\mathrm{CO}_{2}$. Fig. 9 shows the long-term oxygen permeation behavior of the (PL) ${ }_{1.9}$ NCG membrane at 900 and $975{ }^{\circ} \mathrm{C}$, using either $\mathrm{He}$ or pure $\mathrm{CO}_{2}$ as sweep gas. Stable oxygen fluxes with no sign of deterioration are observed over $200 \mathrm{~h}$. Comparing the XRD patterns of the $(\mathrm{PL})_{1.9} \mathrm{NCG}$ membrane before and after the long-term permeation tests revealed no formation of second phases, as shown in Fig. 10. In particular, no evidence of carbonation formation was found. Fig. 11 depicts SEM/EDXS images of a cross-section of the (PL) ${ }_{1.9}$ NCG membrane after the oxygen permeation tests. The results confirm a homogenous distribution of all elements. The observations confirm the excellent stability of (PL) ${ }_{1.9}$ NCG under a $\mathrm{CO}_{2}$ atmosphere. The observed behavior is in marked contrast with many earthalkaline containing perovskite oxides whose oxygen permeation fluxes are found to decrease sharply upon $\mathrm{CO}_{2}$ exposure., ${ }^{9,10}$

\subsection{Influence of A-site deficiency on oxygen transport}

Data from this study demonstrate that A-site deficient (PL) ${ }_{1.9}$ NCG shows superior oxygen transport properties compared to A-site stoichiometric $(\mathrm{PL})_{2.0}$ NCG. As was mentioned in the introduction, similar observations have been reported by Ishihara and colleagues for A-site deficient $\mathrm{Nd}_{1.9}\left(\mathrm{Ni}_{0.75} \mathrm{Cu}_{0.25}\right)_{0.95} \mathrm{Ga}_{0.05} \mathrm{O}_{4}$ and $\mathrm{Pr}_{1.9} \mathrm{Ni}_{0.75} \mathrm{Cu}_{0.25} \mathrm{Ga}_{0.05} \mathrm{O}_{4}$ compared to their A-site stoichiometric forms. ${ }^{\mathbf{2 0 2} 21}$ The latter

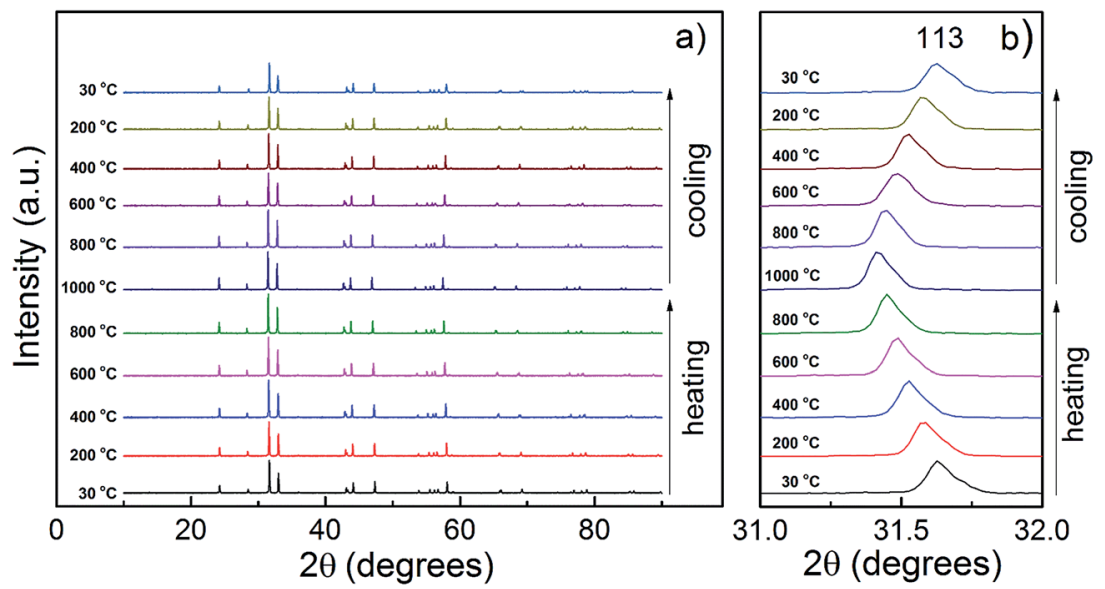

Fig. 3 (a) In-situ high-temperature XRD patterns of calcined $\left(\mathrm{PL}_{1.9}\right) \mathrm{NCG}$ powder collected during exposure to pure $\mathrm{CO}_{2}$, and (b) magnified view of the (113) reflection. Diffractograms were recorded in intervals of $100{ }^{\circ} \mathrm{C}$ while not all are displayed for clarity reasons. 

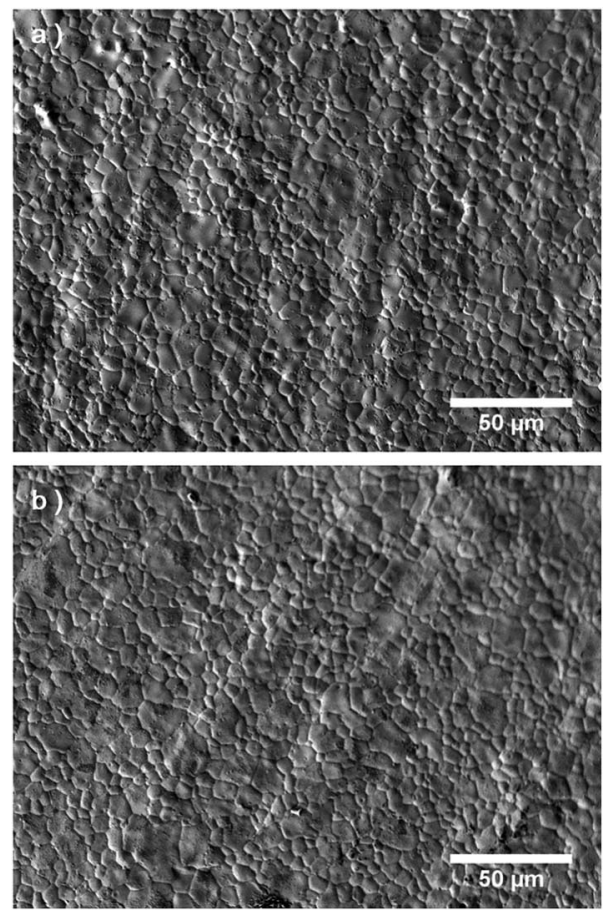

Fig. 4 Surface SEM micrographs of sintered (a) $(\mathrm{PL})_{2.0} \mathrm{NCG}$ and (b) $(\mathrm{PL})_{1.9} \mathrm{NCG}$ membranes.

authors attributed the phenomenon to grain size effects, increased concentration of interstitial oxygen, or enhanced diffusivity of interstitial oxygen. ${ }^{20,21,36}$ It may be noted that the grain sizes found in this study for (PL) ${ }_{1.9} \mathrm{NCG}$ and $(\mathrm{PL})_{2.0} \mathrm{NCG}$ are similar (see Fig. 4), while the oxygen hyperstoichiometry decreases rather than increases by introducing A-site deficiency

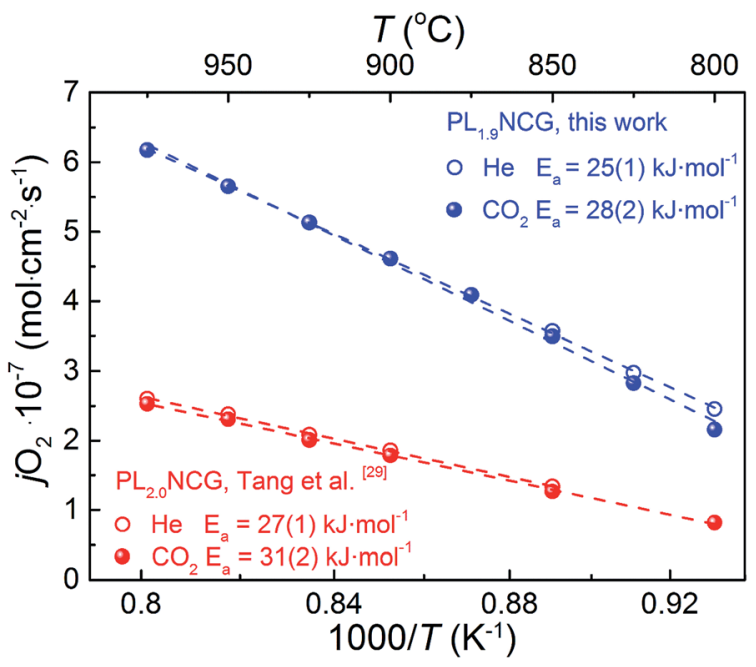

Fig. 5 Temperature dependence of the oxygen permeation flux for $(\mathrm{PL})_{1.9} \mathrm{NCG}$ and $(\mathrm{PL})_{2.0} \mathrm{NCG}$, measured using different sweep gases. Data for both materials were collected under similar conditions. The membrane thicknesses are $0.6 \mathrm{~mm}$. Data for $(\mathrm{PL})_{2.0} \mathrm{NCG}$ were taken from our previous study. ${ }^{29}$ Apparent activation energies are listed in the figure. (see Table 1). Clearly other factors must be taken into to account for the observations.

Hydrogen reduction experiments show that, at $900{ }^{\circ} \mathrm{C}$, $(\mathrm{PL})_{2.0} \mathrm{NCG}$ is hyperstoichiometric with $4+\delta=4.25$, while (PL) ${ }_{1.9} \mathrm{NCG}$ is found to be almost oxygen stoichiometric, $4+\delta=$ 3.98 (Table 1). At the same time the oxygen fluxes through (PL) ${ }_{1.9}$ NCG membranes, in the range of $800-975{ }^{\circ} \mathrm{C}$, exceed those through (PL) ${ }_{2.0}$ NCG membranes by a factor of 2-3 (Fig. 5). Interestingly, despite the apparent lowering in the ionic charge carrier concentration by introducing A-site deficiency, oxygen transport has increased. The results are taken as evidence that the ionic charge carriers in (PL) ${ }_{1.9}$ NCG must exhibit a higher diffusivity that overcompensates the loss in the ionic charge carrier concentration compared to those in (PL) ${ }_{2.0} \mathrm{NCG}$. As the oxygen content of (PL) ${ }_{1.9} \mathrm{NCG}$ is found to be almost stoichiometric, the role of oxygen vacancy diffusion becomes significant. Accordingly, the enhanced oxygen transport observed for (PL) ${ }_{1.9}$ NCG can be accounted for by fast oxygen transport via a vacancy mechanism. Such a conclusion would be consistent with the finding by Cleave et al. that the most likely pathway for oxygen migration in $\mathrm{La}_{2} \mathrm{NiO}_{4}$, i.e., with the lowest activation energy, is a vacancy mechanism, involving transfer between two apical (O2) sites. ${ }^{17}$
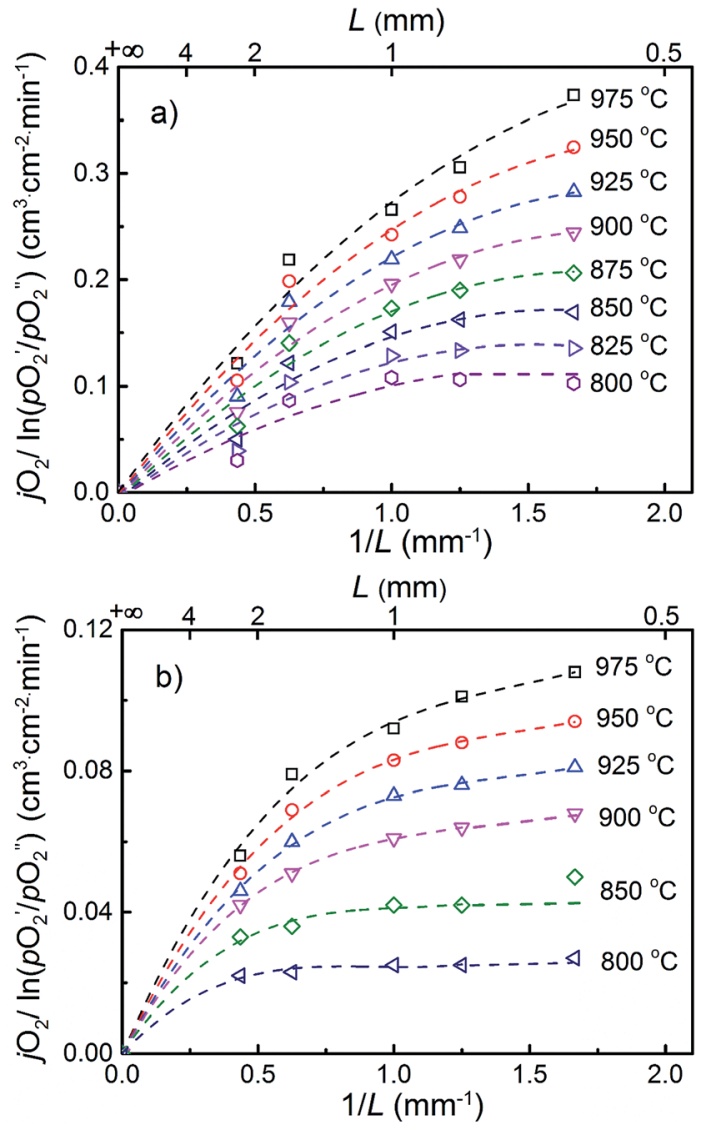

Fig. 6 Dependence of the normalized oxygen flux on the inverse membrane thickness for (a) (PL) ${ }_{1.9} \mathrm{NCG}$ and (b) $(\mathrm{PL})_{2.0} \mathrm{NCG}$. Data for the latter were taken from our previous study. ${ }^{29}$ Note the different vertical scales. 


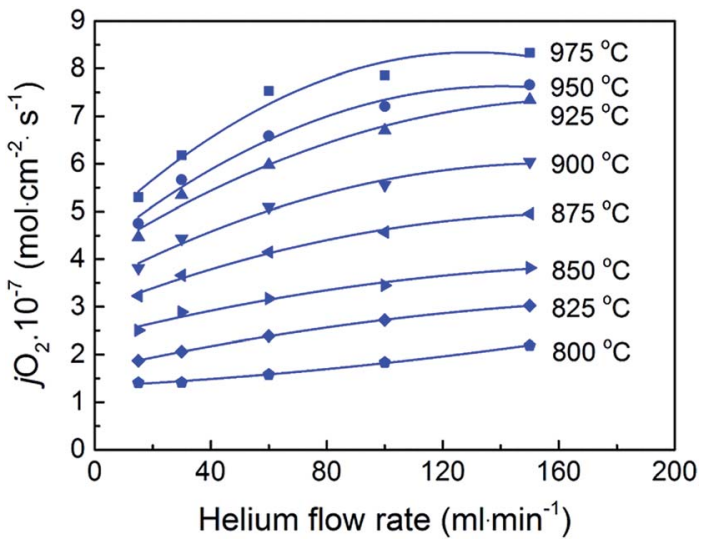

Fig. 7 Dependence of the oxygen flux through a $0.6 \mathrm{~mm}$ thick $(\mathrm{PL})_{1.9} \mathrm{NCG}$ membrane at different temperatures on the He sweep gas flow rate.

The role of a vacancy mechanism in overall oxygen transport in (PL) ${ }_{1.9}$ NCG can be illustrated by simple defect chemical considerations. The concentration of oxygen vacancies is determined by anion Frenkel disorder. Using the standard Kröger-Vink defect notation, this equilibrium can be expressed as

$$
\mathrm{O}_{\mathrm{O}}^{\times}+V_{\mathrm{i}} \rightleftarrows \mathrm{O}^{\prime \prime}{ }_{\mathrm{i}}+V_{\mathrm{O}}^{*}
$$

Close to stoichiometric conditions, i.e., in the regime for dilute defect concentrations, and ignoring defect association, the antiFrenkel equilibrium constant $K_{\mathrm{AF}}$ can be presented as

$$
K_{\mathrm{AF}} \approx\left[\mathrm{O}^{\prime \prime}{ }_{\mathrm{i}}\right]\left[V_{\mathrm{O}}^{\prime \prime}\right] \approx \delta_{\mathrm{i}} \cdot \delta_{\mathrm{v}}
$$

where $\delta_{\mathrm{i}}$ and $\delta_{\mathrm{V}}$ are the molar fractions of oxygen interstitials and oxygen vacancies, respectively. The overall nonstoichiometry parameter is given by $\delta=\delta_{\mathrm{i}}-\delta_{\mathrm{V}}$. Eqn (4) can be used to calculate $\delta_{\mathrm{i}}$ and $\delta_{\mathrm{V}}$ provided that $K_{\mathrm{AF}}$ is known. Data of such calculation, assuming $K_{\mathrm{AF}}=10^{-2}$, are shown in Fig. 12 .

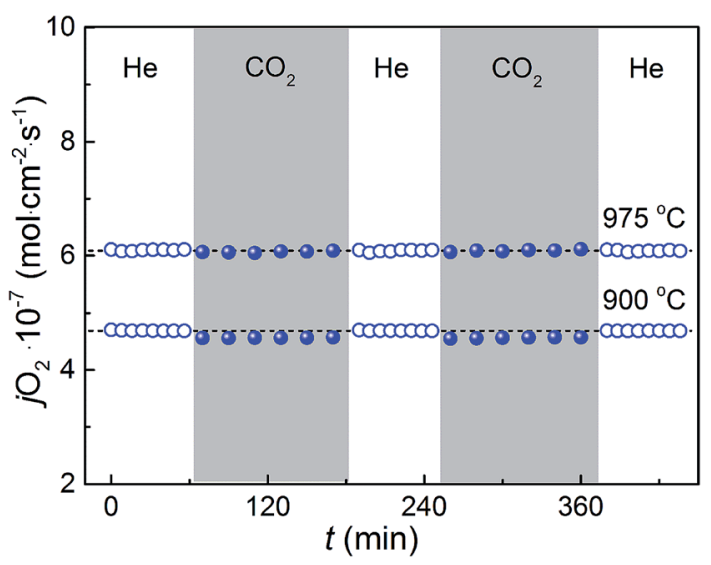

Fig. 8 Oxygen permeation flux through a $0.6 \mathrm{~mm}$ thick $\mathrm{PL}_{1.9} \mathrm{NCG}$ membrane at 900 and $975^{\circ} \mathrm{C}$. Data were collected by periodically changing the sweep gas between $\mathrm{He}$ and $\mathrm{CO}_{2}$. Horizontal dashes lines are guides to the eye.

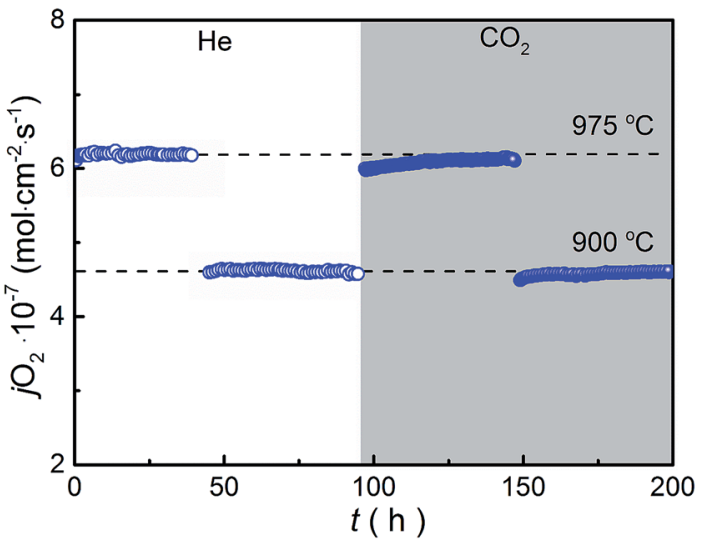

Fig. 9 Long-term stability test of the oxygen permeation flux through a $0.6 \mathrm{~mm}$ thick $(\mathrm{PL})_{1.9} \mathrm{NCG}$ membrane. Data were collected at two different temperatures, using $\mathrm{He}$ and $\mathrm{CO}_{2}$ as sweep gases as indicated in the figure. Horizontal dashed lines are guides to the eye.

The Nernst-Einstein equation can be used to express the ionic conductivity in terms of the defect concentrations and their diffusivities,

$$
\sigma_{\mathrm{i}}=\frac{4 F^{2}}{R T V_{\mathrm{m}}}\left(\delta_{\mathrm{i}} D_{\mathrm{i}}+\delta_{\mathrm{V}} D_{\mathrm{V}}\right)
$$

Where $V_{\mathrm{m}}$ is the molar volume, and $D_{\mathrm{i}}$ and $D_{\mathrm{V}}$ are the diffusivities of interstitials and vacancies, respectively. Eqn (5) can be rewritten into,

$$
\sigma_{\mathrm{i}}=\frac{4 F^{2}}{R T V_{\mathrm{m}}} D_{\mathrm{i}}\left(\delta_{\mathrm{i}}+\delta_{\mathrm{v}} \xi\right)
$$

where we defined the parameter $\xi=D_{\mathrm{V}} / D_{\mathrm{i}}$. The relative magnitudes of the diffusivities affect the overall ionic conductivity, as is illustrated in Fig. 13. If the defect diffusivities are equal $(\xi=1)$, the ionic conductivity is at minimum at the stoichiometric composition $(\delta=0)$. The plot of the ionic conductivity versus $\delta$ obtained for $\xi=1$ is symmetrical about $\delta=0$. With increasing $\xi$, the minimum shifts to higher $\delta$ values. In this case, a higher ionic conductivity is obtained for hypostoichoimetric $(\delta<0)$ than for hyperstoichiometric $(\delta>0)$ compositions of a similar

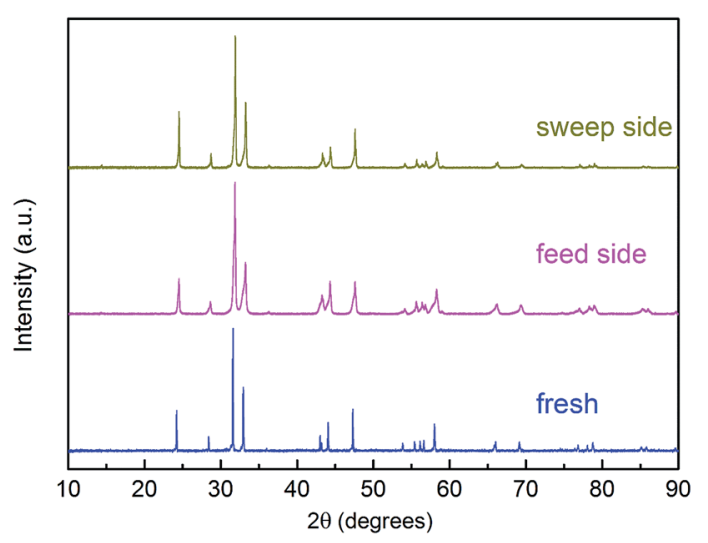

Fig. 10 XRD patterns of fresh and spent $(\mathrm{PL})_{1.9}$ NCG membranes after long-term oxygen permeation tests. 

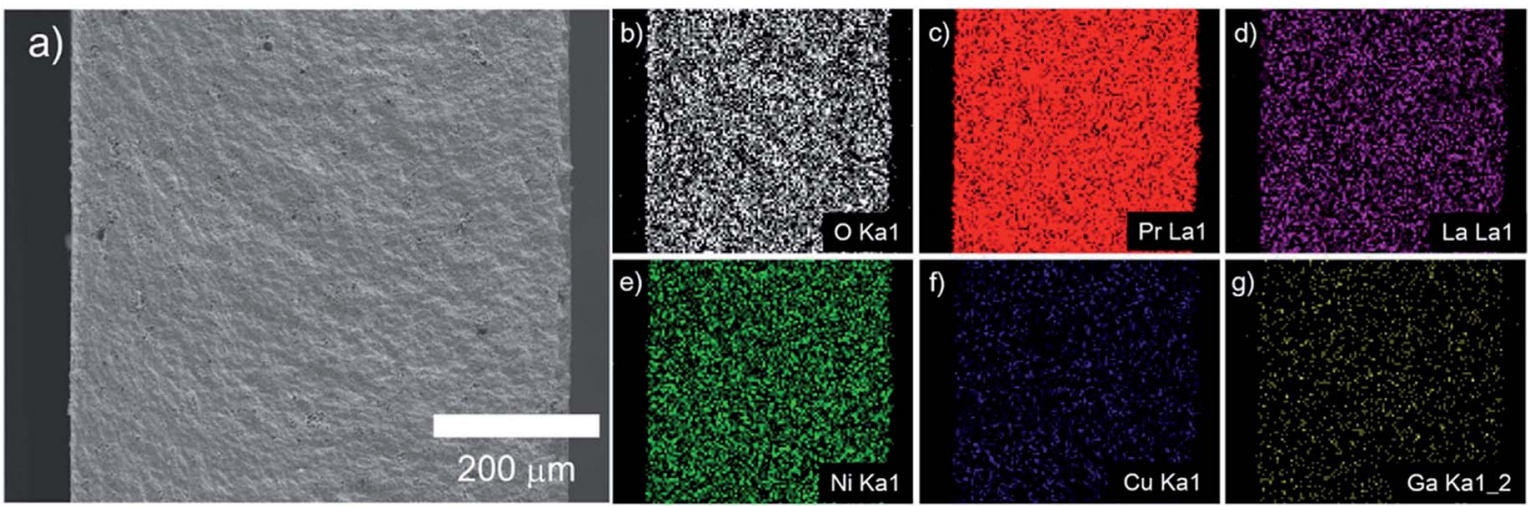

Fig. 11 (a) SEM, and $(b-g)$ EDXS images of a cross-section of the $(P L)_{1.9} N C G$ membrane after the long-term permeation tests.

absolute magnitude. It should be emphasized that the value obtained for $\xi$ is determined by the value of $K_{\mathrm{AF}}$. It is easily demonstrated by calculation that, at given value of $K_{\mathrm{AF}}=10^{-2}, \xi$ must be 10 to yield a two times higher ionic conductivity for $(\mathrm{PL})_{1.9} \mathrm{NCG}$, with $\delta=-0.02$, than for $(\mathrm{PL})_{2.0} \mathrm{NCG}$, with $\delta=0.25$, as is experimentally observed (see Table 1).

In the $\mathrm{A}_{2} \mathrm{BO}_{4}$ oxides (with the $\mathrm{K}_{2} \mathrm{NiF}_{4}$ structure), the interstitial oxygen ions $\mathrm{O} 3$ are in a tetrahedral environment of the A-site cations as well as of the apical oxygen $\mathrm{O} 2 .{ }^{15} \mathrm{MD}$ simulations show only a weak dependence of the diffusivity of oxygen interstitials in $\mathrm{Pr}_{2} \mathrm{NiO}_{4+\delta}$ with the degree of oxygen hyperstoichiometry. ${ }^{37} \mathrm{The}$ observations are consistent with MD simulations of oxygen transport in $\mathrm{La}_{2} \mathrm{NiO}_{4+\delta}{ }^{16}$ Several researchers have investigated the effect of acceptor-doping on the oxygen diffusivity in oxides with the $\mathrm{K}_{2} \mathrm{NiF}_{4}$ structure. Acceptor doping reduces the concentration of oxygen interstitials. The corresponding results of ${ }^{18} \mathrm{O}$ tracer diffusion studies by secondary-ion mass spectroscopy (SIMS) show the oxygen diffusivities in $\mathrm{La}_{2-x} \mathrm{Sr}_{x} \mathrm{NiO}_{4+\delta}$ and

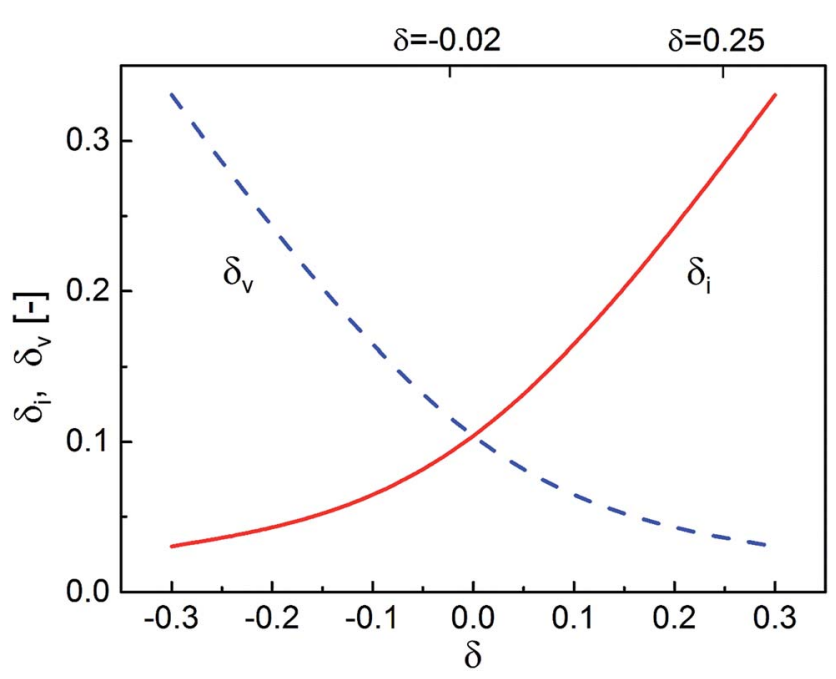

Fig. 12 Concentration of interstitial oxygen ions $\left(\delta_{\mathrm{i}}\right)$ and oxygen vacancies $\left(\delta_{\mathrm{V}}\right)$ as a function of the overall nonstoichiometry parameter $\delta=\delta_{\mathrm{i}}-\delta_{\mathrm{V}}$, calculated using eqn (4), assuming $K_{\mathrm{AF}}=10^{-2}$. Values of $\delta$, which are indicated on the top scale, refer to $(P L)_{1.9} N C G$ and $(\mathrm{PL})_{2.0}$ NCG (see Table 1).
$\mathrm{La}_{2-x} \mathrm{Sr}_{x} \mathrm{CuO}_{4+\delta}$ to be suppressed by several orders of magnitudes below the diffusivities for the undoped materials..$^{12,38-41}$ For small $\mathrm{Sr}$ addition, the observations are explained by the concomitant decrease in the concentration of oxygen interstitials. ${ }^{12,41}$ For the higher $\mathrm{Sr}$ addition $(x \leq 0.2)$, where charge compensation of the acceptor dopant occurs, in part, by the formation of oxygen vacancies, these are explained by the occurrence of defect associates $V_{\mathrm{O}}^{*}-\mathrm{Sr}_{\mathrm{La}}^{\prime}$, or vacancy ordering, due to the electrostatic interactions between oppositely charged oxygen vacancies and dopant cations. These findings are in apparent contrast with those from the present work. Assuming that, on the introduction of A-site deficiency, A-site cation vacancies $\left(V^{\prime \prime \prime}{ }_{p r}\right)$ and oxygen vacancies are formed, defect associates in (PL) ${ }_{1.9}$ NCG are likely on the basis of simple charge considerations. The high oxygen transport rates observed in (PL) $)_{1.9} \mathrm{NCG}$, however, provide no evidence of their detrimental influence on ionic conductivity. Our results are believed to have general relevance for optimizing

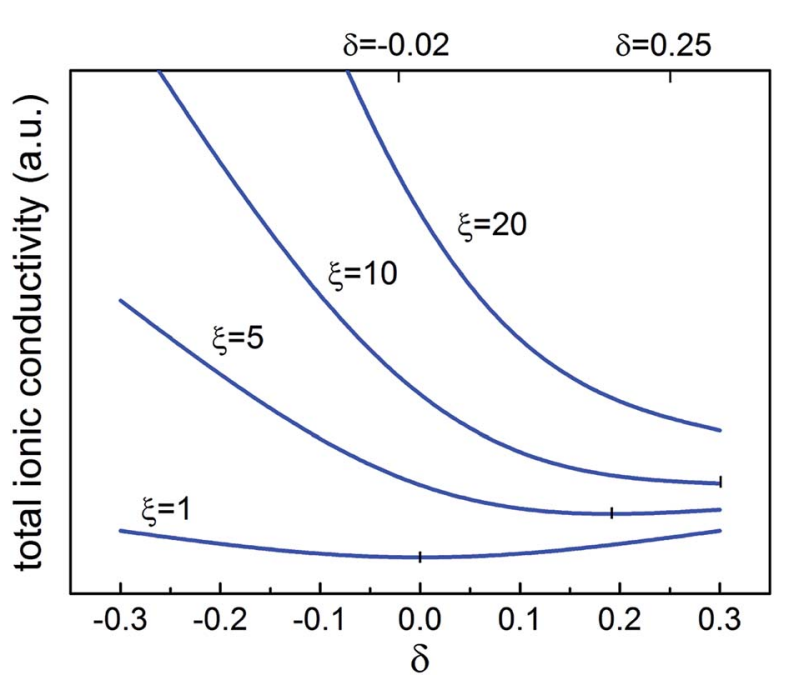

Fig. 13 The influence of oxygen nonstoichiometry on the apparent ionic conductivity calculated for different values of the oxygen vacancy/oxygen interstitial diffusivity ratio $\xi=D_{\vee} / D_{\mathrm{i}}$. Values of $\delta$, which are indicated on the top scale, refer to $(\mathrm{PL})_{1.9} \mathrm{NCG}$ and $(\mathrm{PL})_{2.0} \mathrm{NCG}$ (see Table 1). 
the ionic conductivity of $\mathrm{A}_{2} \mathrm{BO}_{4}$ oxides by tuning the $\mathrm{A} / \mathrm{B}$-site stoichiometry.

\section{Conclusion}

(PL) ${ }_{1.9}$ NCG has been studied with a view to determine the effects of A-site deficiency on structural parameters, oxygen transport and stability under $\mathrm{CO}_{2}$ atmospheres. (PL) ${ }_{1.9} \mathrm{NCG}$ is found to exhibit higher oxygen transport rates compared with its cation stoichiometric parent phase. The high oxygen transport rates are attributed to highly mobile oxygen vacancies and charge compensating cationic vacancies. The high structural stability towards carbonation gives (PL) ${ }_{1.9}$ NCG potential for use as a membrane, e.g., in oxy-fuel combustion processes with $\mathrm{CO}_{2}$ capture. As exemplified in this work, the concept of A-deficiency can be used to optimize oxygen transport in layered $\mathrm{A}_{2} \mathrm{BO}_{4}$ oxides (with the $\mathrm{K}_{2} \mathrm{NiF}_{4}$ structure).

\section{Acknowledgements}

J. X. acknowledges financial support from the China Scholarship Council (CSC), National Science Fund for Distinguished Young Scholars of China (No. 21225625) and the Australian Research Council (ARC) through the Future Fellow Program (FT140100757). Financial support from the German Research Foundation (DFG) (No. FE928/7-1) is appreciated. The authors also greatly acknowledge O. Ravkina, A. Schulz and F. Steinbach for technical support.

\section{Notes and references}

1 J. D. Figueroa, T. Fout, S. Plasynski, H. McIlvried and R. D. Srivastava, Int. J. Greenhouse Gas Control, 2008, 2, 9-20. 2 C. Gough, Int. J. Greenhouse Gas Control, 2008, 2, 155-168.

3 R. Kneer, D. Toporov, M. Förster, D. Christ, C. Broeckmann, E. Pfaff, M. Zwick, S. Engels and M. Modigell, Energy Environ. Sci., 2010, 3, 198-207.

4 X. Tan, K. Li, A. Thursfield and I. S. Metcalfe, Catal. Today, 2008, 131, 292-304.

5 J. Sunarso, S. Baumann, J. M. Serra, W. A. Meulenberg, S. Liu, Y. S. Lin and J. C. Diniz da Costa, J. Membr. Sci., 2008, 320, 13-41.

6 K. Zhang, J. Sunarso, Z. Shao, W. Zhou, C. Sun, S. Wang and S. Liu, RSC Adv., 2011, 1, 1661-1676.

7 L. Qiu, T. H. Lee, L. M. Liu, Y. L. Yang and A. J. Jacobson, Solid State Ionics, 1995, 76, 321-329.

8 Z. Shao, W. Yang, Y. Cong, H. Dong, J. Tong and G. Xiong, J. Membr. Sci., 2000, 172, 177-188.

9 M. Arnold, H. Wang and A. Feldhoff, J. Membr. Sci., 2007, 293, 44-52.

10 J. Yi, M. Schroeder, T. Weirich and J. Mayer, Chem. Mater., 2010, 22, 6246-6253.

11 V. Kharton, A. Kovalevsky, E. Tsipis, A. Viskup, E. Naumovich, J. Jurado and J. Frade, J. Solid State Electrochem., 2002, 7, 30-36.

12 E. Boehm, J. Bassat, P. Dordor, F. Mauvy, J. Grenier and P. Stevens, Solid State Ionics, 2005, 176, 2717-2725.
13 M. Yashima, J. Ceram. Soc. Jpn., 2009, 117, 1055-1059.

14 J. M. Bassat, P. Odier, A. Villesuzanne, C. Marin and M. Pouchard, Solid State Ionics, 2004, 167, 341-347.

15 L. Minervini, R. W. Grimes, J. A. Kilner and K. E. Sickafus, J. Mater. Chem., 2000, 10, 2349-2354.

16 A. Chroneos, D. Parfitt, J. A. Kilner and R. W. Grimes, J. Mater. Chem., 2010, 20, 266.

17 A. R. Cleave, J. A. Kilner, S. J. Skinner, S. T. Murphy and R. W. Grimes, Solid State Ionics, 2008, 179, 823-826.

18 M. Yashima, H. Yamada, S. Nuansaeng and T. Ishihara, Chem. Mater., 2012, 24, 4100-4113.

19 M. Yashima, M. Enoki, T. Wakita, R. Ali, Y. Matsushita, F. Izumi and T. Ishihara, J. Am. Chem. Soc., 2008, 130, 2762-2763.

20 T. Ishihara, N. Sirikanda, K. Nakashima, S. Miyoshi and H. Matsumoto, J. Electrochem. Soc., 2010, 157, B141.

21 A. Kawahara and T. Ishihara, Electrochem. Solid-State Lett., 2010, 13, B76.

22 A. Feldhoff, M. Arnold, J. Martynczuk, T. M. Gesing and H. Wang, Solid State Sci., 2008, 10, 689-701.

23 J. Xue, Q. Liao, Y. Wei, Z. Li and H. Wang, J. Membr. Sci., 2013, 443, 124-130.

24 W. Chen, A. Nijmeijer and L. Winnubst, Solid State Ionics, 2012, 229, 54-58.

25 H. Luo, B. Tian, Y. Wei, H. Wang, H. Jiang and J. Caro, AIChE J., 2010, 56, 604-610.

26 J. Xue, Q. Zheng, Y. Wei, K. Yuan, Z. Li and H. Wang, Ind. Eng. Chem. Res., 2012, 51, 4703-4709.

27 H. Wang, R. Wang, D. T. Liang and W. Yang, J. Membr. Sci., 2004, 243, 405-415.

28 C. Tablet, G. Grubert, H. Wang, T. Schiestel, M. Schroeder, B. Langanke and J. Caro, Catal. Today, 2005, 104, 126-130.

29 J. Tang, Y. Wei, L. Zhou, Z. Li and H. Wang, AIChE J., 2012, 58, 2473-2478.

30 Y. Wei, O. Ravkina, T. Klande, H. Wang and A. Feldhoff, J. Membr. Sci., 2013, 429, 147-154.

31 W. Cheikh-Rouhou Koubaa, M. Koubaa, A. Cheikh-Rouhou, W. Boujelben and A. M. Haghiri-Gosnet, J. Alloys Compd., 2008, 455, 67-72.

32 W. Zhou, R. Ran, Z. Shao, W. Jin and N. Xu, J. Power Sources, 2008, 182, 24-31.

33 K. Shan and X.-M. Guo, Mater. Lett., 2013, 113, 126-129.

34 X. Tan, N. Liu, B. Meng, J. Sunarso, K. Zhang and S. Liu, J. Membr. Sci., 2012, 389, 216-222.

35 C. Wagner, Z. Phys. Chem. B, 1933, 21, 25-41.

36 S. Miyoshi, T. Furuno, O. Sangoanruang, H. Matsumoto and T. Ishihara, J. Electrochem. Soc., 2007, 154, B57.

37 D. Parfitt, A. Chroneos, J. A. Kilner and R. W. Grimes, Phys. Chem. Chem. Phys., 2010, 12, 6834-6836.

38 Z. Li, R. Haugsrud and T. Norby, Solid State Ionics, 2011, 184, 42-46.

39 E. J. Opila, H. L. Tuller, B. J. Wuensch and J. Maier, J. Am. Ceram. Soc., 1993, 76, 2363-2369.

40 J. Routbort, S. Rothman, B. Flandermeyer, L. Nowicki and J. Baker, J. Mater. Res., 1988, 3, 116-121.

41 S. J. Skinner and J. A. Kilner, Solid State Ionics, 2000, 135, 709-712. 